\title{
The prognostic value of D-dimer levels in endometrial cancer patients treated with intensity-modulated radiation therapy
}

\author{
Xiaojing Yang ${ }^{1, *}$, Hanru Ren ${ }^{2, *}$, Yi Sun ${ }^{1}$, Lihua Zhang ${ }^{1}$, Xinmiao Yang ${ }^{1}$, Hongling Li ${ }^{1}$, \\ Yuhui Shao ${ }^{1}$, Jie Fu ${ }^{1}$ \\ ${ }^{1}$ Department of Radiation Oncology, Shanghai Jiao Tong University Affiliated Sixth People's Hospital, Shanghai, China \\ ${ }^{2}$ Department of Orthopaedics, Shanghai Pudong Hospital, Fudan University, Pudong Medical Center, Shanghai, China \\ *These authors have contributed equally to this work \\ Correspondence to: Xiaojing Yang, email: youngshanghai@126.com
}

Keywords: D-dimer, endometrial cancer, prognosis, intensity-modulated radiation therapy

Received: November 04, $2016 \quad$ Accepted: February 08, $2017 \quad$ Published: February 28, 2017

Copyright: Yang et al. This is an open-access article distributed under the terms of the Creative Commons Attribution License (CC-BY), which permits unrestricted use, distribution, and reproduction in any medium, provided the original author and source are credited

\section{ABSTRACT}

Explain the important role of plasma D-dimer in cancers. Plasma D-dimer is increased in various tumors. However, the predictive value of plasma D-dimer is unclear. This study is aimed to evaluate the prognostic value of the D-dimer level in patients managed with intensity-modulated radiation for endometrial cancer. The D-dimer levels of forty patients with endometrial cancer were assessed before (D1) and after (D2) intensity-modulated radiation therapy (IMRT), respectively. The D-dimer level changes ( $\Delta D)$ were defined as D2 minus D1. Cox regression and logrank tests were used to evaluate the $D$-dimer levels in relation to progression free survival (PFS) and overall survival (OS). The OS and PFS of patients with a low D1 were significantly longer than those with a high $D 1(P<0.001, P<0.001)$. We saw the similar correlation between D2, PFS and OS $(P<0.001, P<0.001)$. Multivariate survival analyses showed that $D$-dimer was independently associated with 05 and PFS in patients with endometrial cancer. The $\triangle D$ level was not related to the OS and PFS in endometrial cancer patients. The levels of D-dimer may be considered as an important predictor of PFS and OS in endometrial cancer patients treated with IMRT.

\section{INTRODUCTION}

Endometrial cancer is a common gynaecological malignancies [1]. Although hysterectomy is the first choice of treatment for endometrial cancer, postoperative pelvic radiotherapy and intensity-modulated radiation therapy (IMRT) is becoming popular and improve the clinical outcome [2]. However, the clinical outcome is not remarkable improved after IMRT in most patients. Biomarkers may enable the identification of endometrial cancer patients who are likely to benefit from IMRT [3]. Thus, development of simple and accurate prediction makers for the prognosis of endometrial cancer patients treated with IMRT after hysterectomy.

Tumor cells activate the coagulation pathway in endothelial cells, resulting in the secretion of procoagulants and a secondary increase of fibrinolysis and fibrin degradation product D-dimer $[4,5]$. D-dimer stimulates the growth of malignancies via promoting tumor cell proliferation, adhesion and angiogenesis [6]. Several studies report that the level of D-dimer is increased in breast [7], gastric [8], colorectal [9], lung [10], and nasopharyngeal carcinomas [11], and is correlated with a poor prognosis and decreased response to treatment. However, the relation of D-dimer levels to the survival of patients with endometrial cancer has not been reported.

In this study, the plasma D-dimer levels were measured in patients treated with hysterectomy and postoperational IMRT for endometrial cancer. The prediction value of $\mathrm{D}$-dimer in relation to progression free survival (PFS) and overall survival (OS) was also investigated. 


\section{RESULTS}

\section{Clinicopathological features}

Forty patients with complete clinical data were included in this study. The median age was 56 years (range, 32-76). Clinicopathologic characteristics were shown in Table $1.77 .5 \%$ of the patients had a body mass index (BMI) index $\geq 25$. Five percent of people had a history of smoking. The percent of patients had hypertensive and diabetic mellitus diseases were $72.5 \%$ and $67.5 \%$, respectively. More than half of the patients had a family history of tumor diseases. 67.5\% (27/40) of the patients had a Karnofsky Performance Scale (KPS) score $\geq 80$. The plasma D-dimer level before (D1) and after IMRT (D2) were collected in 40 patients with endometrial cancer. The median D1, D2, and the difference in D-dimer levels $(\Delta \mathrm{D})$ were 2.42 (range 0.14-17.66) $\mathrm{mg} / \mathrm{L}, 2.97$ (range $0.13-21.37$ ) $\mathrm{mg} / \mathrm{L}$, and 1.51 (range-1.36-9.0) mg/L, respectively. Based on the ROC analyses, the best cut-off value of $\mathrm{D} 1, \mathrm{D} 2$, and $\Delta \mathrm{D}$ were $1.82 \mathrm{mg} / \mathrm{L}, 1.90 \mathrm{mg} / \mathrm{L}$, and $0.77 \mathrm{mg} / \mathrm{L}$, respectively.

\section{Univariate and multivariate analyses of prognostic factors}

The data of the univariable analyses were shown in Table 2. We found that International Federation of Gynecology and Obstetrics (FIGO) stage $(P<0.001, P<$ $0.001)$, histologic grade $(P=0.001, P<0.001)$, depth of myometrial invasion (MI) $(P<0.001, P<0.001)$, lymph node metastasis $(P=0.001, P<0.001), \mathrm{D} 1(P<0.001, P$ $<0.001)$, and D2 $(P<0.001, P<0.001)$ were significantly associated with OS and PFS. Multivariate analysis using the Cox proportional hazards model demonstrated that FIGO stage (hazard ratio $(\mathrm{HR})=33.338,95 \%$ confidence interval (CI): $0.259-49.805, P=0.001$; HR $=23.293,95 \%$ CI: $0.374-$ 541.274, $P<0.001$, respectively), D1 (HR=33.530, $95 \%$ CI: 2.319-42.066, $P<0.001$; HR=13.978, $95 \%$ CI: 1.080 $27.588, P=0.001$, respectively) as well as $\mathrm{D} 2(\mathrm{HR}=8.121$, $95 \%$ CI: $-10.938-31.372, P=0.031$; HR $=9.924,95 \% \mathrm{CI}$ : $-4.580-29.401, P=0.036$, respectively) were independent prognostic indicator of OS and PFS (Table 3).

\section{D-dimer as a prognostic factor of survival}

Kaplan-Meier analysis was performed to the levels of D-dimer on D1, D2 in relation to patients' survivals. Based on the cut-off values described above, we divided patients into subgroups with lower level of D-dimer or higher level of D-dimer. The median OS and PFS times of all patients were 48 and 32 months, respectively. The Kaplan-Meier survival curves indicated that the OS and PFS of patients with a higher level of D-dimer on D1 were significantly shorter than those with a lower level on D1 (Figure 1A, B, $P<0.001, P<0.001$, respectively). Similar correlation was found between OS and PFS and D-dimer on D2 (Figure
Table 1: Clinicopathologic characteristics

\begin{tabular}{|c|c|}
\hline Characteristics & $\begin{array}{l}\text { Median (25th-75th } \\
\text { percentile) or no. }(\%)\end{array}$ \\
\hline Median age, years (range) & $56(32-76)$ \\
\hline \multicolumn{2}{|l|}{ BMI $(\mathrm{kg} / \mathrm{m} 2)$} \\
\hline$<25$ & $9(22.5 \%)$ \\
\hline$\geq 25$ & $31(77.5 \%)$ \\
\hline \multicolumn{2}{|l|}{ Smoking } \\
\hline No & $38(95.0 \%)$ \\
\hline Yes & $2(5.0 \%)$ \\
\hline \multicolumn{2}{|l|}{ Hypertensive } \\
\hline No & $11(27.5 \%)$ \\
\hline Yes & $29(72.5 \%)$ \\
\hline \multicolumn{2}{|l|}{ Diabetic Mellitus } \\
\hline No & $13(32.5 \%)$ \\
\hline Yes & $27(67.5 \%)$ \\
\hline \multicolumn{2}{|l|}{ Family History of Cancers } \\
\hline No & $17(42.5 \%)$ \\
\hline Yes & $23(57.5 \%)$ \\
\hline \multicolumn{2}{|l|}{ KPS } \\
\hline$<80$ & $13(32.5 \%)$ \\
\hline$\geq 80$ & $27(67.5 \%)$ \\
\hline \multicolumn{2}{|l|}{ Test } \\
\hline $\mathrm{D} 1(\mathrm{mg} / \mathrm{L})$ & $2.42(0.14-17.66)$ \\
\hline $\mathrm{D} 2(\mathrm{mg} / \mathrm{L})$ & $2.97(0.13-21.37)$ \\
\hline$\Delta \mathrm{D}(\mathrm{mg} / \mathrm{L})$ & $1.51(-1.36-9.08)$ \\
\hline
\end{tabular}

Abbreviations: Body mass index: BMI; Karnofsky Performance Scale: KPS; D-dimer level before radition: D1; D-dimer level after radition: D2; Change in D-dimer level (D2 minus D1): $\Delta \mathrm{D}$.

$1 \mathrm{C}, \mathrm{D}, P<0.001, P<0.001$, respectively). There was no differences in OS and PFS between patients with a higher $\Delta \mathrm{D}$ and lower $\Delta \mathrm{D}$ (Figure 1E, $1 \mathrm{~F}, P=0.108, P=0.166$, respectively). As shown in Figure $1 \mathrm{G}, 1 \mathrm{H}$, endometrial cancer patients in early stage had better prognosis.

Moreover, to detect the prognostic value of D-dimer in endometrial cancer patients, the premonitory affection of the levels of D-dimer on D1 and D2 were analyzed in the subgroup stratified by the FIGO stage II-IV. The mean concentrations of D-dimer on D1 in patients with FIGO stage II, III, IV stages were $0.33 \pm 0.54 \mathrm{mg} / \mathrm{L}, 1.76 \pm 1.90 \mathrm{mg} / \mathrm{L}$, $3.81 \pm 4.33 \mathrm{mg} / \mathrm{L}$, respectively. The mean concentrations of D-dimer on D2 in patients with FIGO stage II, III, IV stages were $1.89 \pm 2.02 \mathrm{mg} / \mathrm{L}, \quad 3.12 \pm 4.61 \mathrm{mg} / \mathrm{L}, \quad 6.71 \pm 6.04 \mathrm{mg} / \mathrm{L}$, 
Table 2: Univariate analysis of factors associated with OS and PFS

\begin{tabular}{|c|c|c|c|c|c|}
\hline & \multirow[t]{2}{*}{ Cases (n) } & \multicolumn{2}{|c|}{ OS } & \multicolumn{2}{|c|}{ PFS } \\
\hline & & percent & $P$-value & percent & $P$-value \\
\hline \multicolumn{6}{|l|}{ Age(years) } \\
\hline$<55$ & 19 & $42.1 \%$ & 0.185 & $42.1 \%$ & 0.286 \\
\hline$\geq 55$ & 21 & $23.8 \%$ & & $28.6 \%$ & \\
\hline \multicolumn{6}{|l|}{ Smoking } \\
\hline No & 38 & $52.6 \%$ & 0.382 & $42.1 \%$ & 0.205 \\
\hline Yes & 2 & $50 \%$ & & $0 \%$ & \\
\hline \multicolumn{6}{|c|}{ Hypertensive } \\
\hline No & 11 & $63.6 \%$ & 0.211 & $54.5 \%$ & 0.179 \\
\hline Yes & 29 & $55.2 \%$ & & $41.4 \%$ & \\
\hline \multicolumn{6}{|c|}{ Diabetic Mellitus } \\
\hline No & 13 & $61.5 \%$ & 0.105 & $53.8 \%$ & 0.146 \\
\hline Yes & 27 & $37.0 \%$ & & $33.3 \%$ & \\
\hline \multicolumn{6}{|c|}{ Family History of Cancers } \\
\hline No & 17 & $64.7 \%$ & 0.091 & $70.6 \%$ & 0.076 \\
\hline Yes & 23 & $34.8 \%$ & & 30.45 & \\
\hline \multicolumn{6}{|l|}{ FIGO stage } \\
\hline II & 18 & $66.7 \%$ & $<0.001$ & $72.2 \%$ & $<0.001$ \\
\hline III & 10 & $10.0 \%$ & & $10.0 \%$ & \\
\hline IV & 12 & $0.0 \%$ & & $0.0 \%$ & \\
\hline \multicolumn{6}{|c|}{ Histologic grade } \\
\hline G1 & 20 & $60.0 \%$ & 0.001 & $65.0 \%$ & $<0.001$ \\
\hline G2 & 11 & $8.3 \%$ & & $8.3 \%$ & \\
\hline G3 & 9 & $0.0 \%$ & & $0.0 \%$ & \\
\hline \multicolumn{6}{|l|}{ Depth of MI } \\
\hline$<50 \%$ & 25 & $52.0 \%$ & $<0.001$ & $56.0 \%$ & $<0.001$ \\
\hline$\geq 50 \%$ & 15 & $0.0 \%$ & & $0.0 \%$ & \\
\hline \multicolumn{6}{|c|}{ Lymph node metastasis } \\
\hline No & 22 & $54.5 \%$ & 0.001 & $59.1 \%$ & $<0.001$ \\
\hline Yes & 18 & $5.6 \%$ & & $5.6 \%$ & \\
\hline \multicolumn{6}{|c|}{ BMI (kg/m2) } \\
\hline$<25$ & 9 & $33.3 \%$ & 0.624 & $44.4 \%$ & 0.381 \\
\hline$\geq 25$ & 31 & $32.3 \%$ & & $32.3 \%$ & \\
\hline \multicolumn{6}{|l|}{ ER } \\
\hline Negative & 19 & $31.2 \%$ & 0.587 & $21.1 \%$ & 0.076 \\
\hline Positive & 21 & $33.3 \%$ & & $47.6 \%$ & \\
\hline
\end{tabular}




\begin{tabular}{|c|c|c|c|c|c|}
\hline & \multirow[t]{2}{*}{ Cases (n) } & \multicolumn{2}{|c|}{ OS } & \multicolumn{2}{|c|}{ PFS } \\
\hline & & percent & $P$-value & percent & $P$-value \\
\hline \multicolumn{6}{|l|}{ PR } \\
\hline Negative & 17 & $47.1 \%$ & 0.089 & $52.9 \%$ & 0.044 \\
\hline Positive & 23 & $21.7 \%$ & & $21.7 \%$ & \\
\hline \multicolumn{6}{|l|}{ D1 } \\
\hline low & 23 & $56.5 \%$ & $<0.001$ & $60.7 \%$ & $<0.001$ \\
\hline high & 17 & $0.0 \%$ & & $0.0 \%$ & \\
\hline \multicolumn{6}{|l|}{ D2 } \\
\hline low & 17 & $76.5 \%$ & $<0.001$ & $82.4 \%$ & $<0.001$ \\
\hline high & 23 & $0.0 \%$ & & $0.0 \%$ & \\
\hline \multicolumn{6}{|l|}{$\Delta \mathrm{D}$} \\
\hline low & 27 & $40.7 \%$ & 0.105 & $44.4 \%$ & 0.071 \\
\hline high & 13 & $15.4 \%$ & & $15.4 \%$ & \\
\hline \multicolumn{6}{|l|}{ KPS } \\
\hline$<80$ & 13 & $30.8 \%$ & 0.584 & $30.8 \%$ & 0.491 \\
\hline$\geq 80$ & 27 & $33.3 \%$ & & $37.0 \%$ & \\
\hline
\end{tabular}

Abbreviations: D-dimer level before radition: D1; D-dimer level after radition: D2; Change in D-dimer level (D2 minus D1): $\Delta \mathrm{D}$; International Federation of Gynecology and Obstetrics: FIGO; G1: Well; G2: Moderate; G3: Poor; Myometrial invasion: MI; Body mass index: BMI; Estrogen receptor: ER; Progesterone receptor: PR; Progression-free survival: PFS; Overall

Table 3: Multivariate analysis of factors associated with OS and PFS

\begin{tabular}{lcccccc}
\hline & \multicolumn{3}{c}{ OS } & \multicolumn{3}{c}{ PFS } \\
\cline { 2 - 7 } & $\mathbf{9 5 \%}$ CI & HR & $\boldsymbol{P}$ & $\mathbf{9 5 \%}$ CI & HR & $\boldsymbol{P}$ \\
\hline Age & $-11.307-3.428$ & 0.3 & 0.104 & $-14.456-1.945$ & 0.2 & 0.045 \\
FIGO stage & $0.259-49.805$ & 33.3 & 0.001 & $0.374-541.274$ & 23.3 & 0.000 \\
Histologic grade & $-20.704-7.627$ & 0.6 & 0.049 & $-16.556-4.512$ & 0.4 & 0.192 \\
Depth of MI & $-16.325-13.405$ & 0.8 & 0.807 & $-9.019-13.257$ & 0.9 & 0.911 \\
Lymph node & $-34.856-3.880$ & 0.3 & 0.240 & $-25.089-4.635$ & 0.4 & 0.486 \\
metastasis & $-4.950-19.910$ & 1.8 & 0.352 & $-1.512-17.916$ & 1.8 & 0.358 \\
BMI & $2.319-42.066$ & 33.5 & 0.000 & $1.080-27.588$ & 14.0 & 0.001 \\
D1 & $-10.938-31.372$ & 8.1 & 0.031 & $-4.580-29.401$ & 9.9 & 0.036 \\
D2 & $-19.473-2.738$ & 0.3 & 0.069 & $-18.178-1.014$ & 0.3 & 0.029 \\
$\Delta$ D & $-1.599-21.148$ & 1.6 & 0.079 & $-2.464-15.843$ & 1.8 & 0.329 \\
KPS & & & & & \\
\hline
\end{tabular}

Abbreviations: D-dimer level before radition: D1; D-dimer level after radition: D2; Change in D-dimer level (D2 minus D1): $\Delta \mathrm{D}$; International Federation of Gynecology and Obstetrics: FIGO; Myometrial invasion: MI; Body mass index: BMI; Progression-free survival: PFS; Overall survival: OS; Karnofsky Performance Scale: KPS 

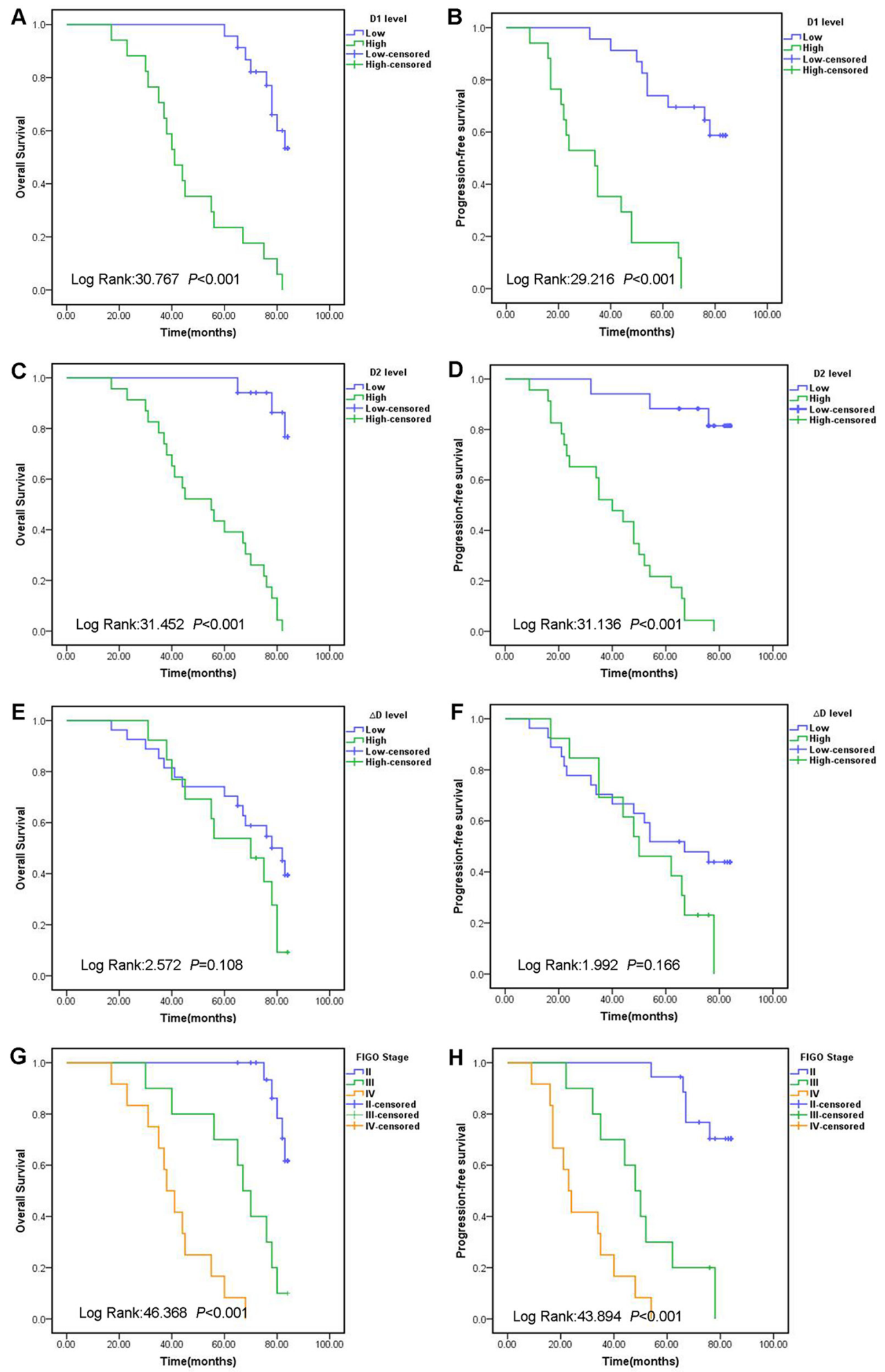

Figure 1: Kaplan-Meier survival curves for OS and PFS for endometrial cancer patients according to D1 levels (A, B), D2 levels (C, D), $\Delta$ D levels (E, F), and different FIGO stage (G, H). Abbreviations: Overall survival: OS; Progression free survival: PFS; D-dimer level before radition: D1; D-dimer level after radition: D2; Change in D-dimer level (D2 minus D1): $\Delta \mathrm{D}$; International Federation of Gynecology and Obstetrics: FIGO. 

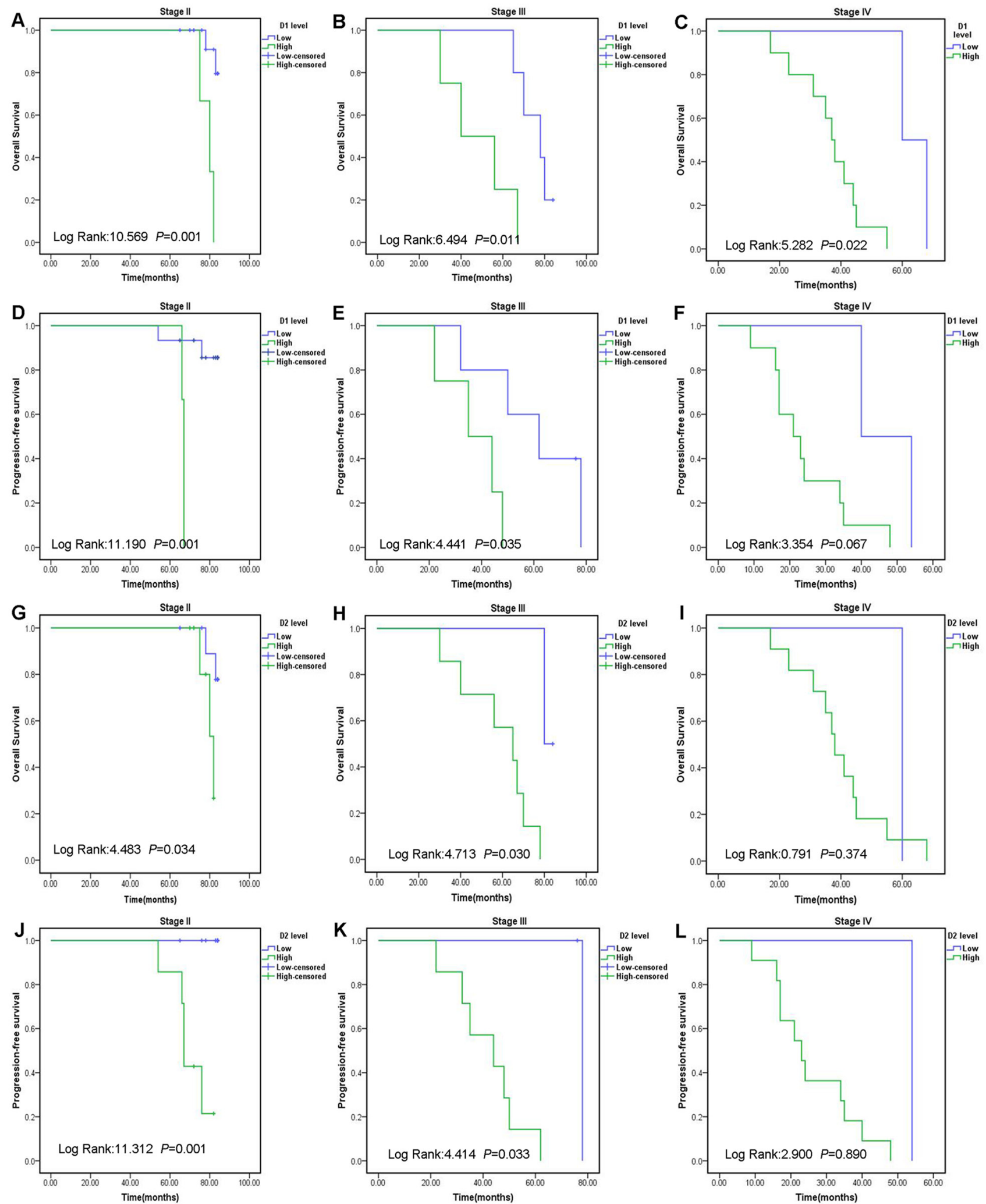

Figure 2: Prognostic significance of D-dimer in endometrial cancer patients according to the different FIGO stages. Patients were divided into low and high groups based on the D1 or D2 levels cut-off values. The OS and PFS rate were calculated by the Kaplan-Meier method and analyzed by the log-rank test. Abbreviations: International Federation of Gynecology and Obstetrics: FIGO. D-dimer level before radition: D1; D-dimer level after radition: D2; Overall survival: OS; Progression-free survival: PFS. 
Table 4: Relationship between D-dimer level and the clinicopathological variables

\begin{tabular}{|c|c|c|c|c|c|c|c|c|c|c|}
\hline & \multirow[t]{2}{*}{ Cases (n) } & \multicolumn{2}{|c|}{ D1 } & \multirow[t]{2}{*}{$P$} & \multicolumn{2}{|c|}{ D2 } & \multirow[t]{2}{*}{$P$} & \multicolumn{2}{|c|}{$\Delta \mathrm{D}$} & \multirow[t]{2}{*}{$P$} \\
\hline & & Low & High & & Low & High & & Low & High & \\
\hline \multicolumn{11}{|l|}{ Age(years) } \\
\hline$<55$ & 19 & 11 & 8 & 0.607 & 9 & 10 & 0.393 & 12 & 7 & 0.413 \\
\hline$\geq 55$ & 21 & 12 & 9 & & 8 & 13 & & 15 & 6 & \\
\hline \multicolumn{11}{|l|}{ FIGO stage } \\
\hline II & 18 & 15 & 3 & 0.001 & 15 & 3 & $<0.001$ & 15 & 3 & 0.064 \\
\hline III & 10 & 6 & 4 & & 2 & 8 & & 4 & 6 & \\
\hline IV & 12 & 2 & 10 & & 0 & 12 & & 8 & 4 & \\
\hline \multicolumn{11}{|c|}{ Histologic grade } \\
\hline G1 & 20 & 16 & 4 & 0.009 & 15 & 5 & $<0.001$ & 16 & 4 & 0.145 \\
\hline $\mathrm{G} 2$ & 11 & 5 & 6 & & 2 & 9 & & 5 & 6 & \\
\hline G3 & 9 & 2 & 7 & & 0 & 9 & & 6 & 3 & \\
\hline \multicolumn{11}{|l|}{ Depth of MI } \\
\hline$<50 \%$ & 25 & 20 & 5 & $<0.001$ & 17 & 8 & $<0.001$ & 17 & 8 & 0.599 \\
\hline$\geq 50 \%$ & 15 & 3 & 12 & & 0 & 15 & & 10 & 5 & \\
\hline \multicolumn{11}{|l|}{$\begin{array}{l}\text { Lymph node } \\
\text { metastasis }\end{array}$} \\
\hline No & 22 & 18 & 4 & 0.001 & 16 & 6 & $<0.001$ & 16 & 6 & 0.329 \\
\hline Yes & 18 & 5 & 13 & & 1 & 17 & & 11 & 7 & \\
\hline \multicolumn{11}{|c|}{ BMI (kg/m2) } \\
\hline$<25$ & 9 & 5 & 4 & 0.594 & 4 & 5 & 0.590 & 5 & 4 & 0.314 \\
\hline$\geq 25$ & 31 & 18 & 13 & & 13 & 18 & & 22 & 9 & \\
\hline \multicolumn{11}{|l|}{ ER } \\
\hline Negative & 19 & 9 & 10 & 0.181 & 6 & 13 & 0.157 & 13 & 6 & 0.587 \\
\hline Positive & 21 & 14 & 7 & & 11 & 10 & & 14 & 7 & \\
\hline \multicolumn{11}{|l|}{ PR } \\
\hline Negative & 17 & 12 & 5 & 0.132 & 10 & 7 & 0.070 & 14 & 3 & 0.082 \\
\hline Positive & 23 & 11 & 12 & & 7 & 16 & & 13 & 10 & \\
\hline \multicolumn{11}{|l|}{ PFS } \\
\hline Yes & 14 & 14 & 0 & $<0.001$ & 14 & 0 & $<0.001$ & 12 & 2 & 0.071 \\
\hline No & 26 & 9 & 17 & & 3 & 23 & & 15 & 11 & \\
\hline \multicolumn{11}{|l|}{ OS } \\
\hline Yes & 13 & 13 & 0 & $<0.001$ & 13 & 0 & $<0.001$ & 11 & 2 & 0.105 \\
\hline No & 27 & 10 & 17 & & 4 & 23 & & 16 & 11 & \\
\hline
\end{tabular}

Abbreviations: D-dimer level before radition: D1; D-dimer level after radition: D2; Change in D-dimer level (D2 minus D1): $\triangle \mathrm{D}$; International Federation of Gynecology and Obstetrics: FIGO; G1: Well; G2: Moderate; G3: Poor; Myometrial invasion: MI; Body mass index: BMI; Estrogen receptor: ER; Progesterone receptor: PR; Progression-free survival: PFS; Overall survival: OS 
Table 5: Differences in D-dimer levels in patients with PD and SD

\begin{tabular}{lccc}
\hline Response $(\mathbf{n}=\mathbf{4 0})$ & D1 $(\mathbf{m g} / \mathbf{L})$ & D2 $(\mathbf{m g} / \mathbf{L})$ & $\boldsymbol{P}$ \\
\hline PD $(\mathrm{n}=26)$ & $2.84 \pm 5.06$ & $5.14 \pm 5.77$ & 0.003 \\
$\mathrm{SD}(\mathrm{n}=14)$ & $1.42 \pm 1.79$ & $0.68 \pm 1.13$ & 0.032 \\
$P$ & 0.761 & 0.002 & \\
\hline
\end{tabular}

Abbreviations: stable disease: SD; progressive disease: PD; D-dimer level before radition: D1; D-dimer level after radition: D2.

respectively. Patients with a higher level of D-dimer on D1 or D2 had remarkably shorter OS and PFS than the patients with a lower level of D-dimer on D1 or D2 level in patients with the stage II and III subgroups (Figure 2). As shown in Table 4, the levels of D-dimer on D1 and D2 were closely related to FIGO stage $(P=0.001 ; P<0.001)$, histologic grade $(P=0.009 ; P<0.001)$, depth of $\mathrm{MI}(P<0.001 ; P<0.001)$, lymph node metastasis $(P=0.001 ; P<0.001)$, PFS $(P<0.001$; $P<0.001)$ and $\mathrm{OS}(P<0.001 ; P<0.001)$. However, there was no association between the levels of D-dimer on D1 and D2 and other prognostic factors such as age, BMI, ER, PR expression. $\triangle \mathrm{D}$ levels had no correlation to the above factors.

\section{The relationship between D-dimer and IMRT response}

We further assessed the relation between $\Delta \mathrm{D}$ and IMRT response. The mean D2 level reduced by $0.74 \mathrm{mg} / \mathrm{L}$ compared to the D1 level in 14 patients with stable disease (SD, $P=0.032$, Table 5). The mean D2 in 26 patients with progressive disease (PD) increased by $2.30 \mathrm{mg} / \mathrm{L}$ contradistinguished with the D1 $(P=0.003)$. The progression disease was significantly related to the increase of D-dimer after IMRT. Our data exhibited that the D-dimer level may be considered as a predictor for IMRT response in endometrial cancer patients.

\section{DISCUSSION}

Blood coagulation and fibrinolytic system play a significant role in tumor progression [12]. D-dimer serves as an indicator of fibrinolytic pathway activation, which is related to unfavorable prognosis in several cancers [7-10, $13,14]$. Our study is the study to investigate the correlation between D-dimer and survival in patients with endometrial cancer. Our data show that plasma D-dimer level is a predictor for the prognosis in endometrial cancer patients.

Furthermore, D-dimer level was also a prognosis marker in different FIGO stage subgroups. However, there was no statistical significance between the D-dimer level and stage IV group, which may be explained by the small sample size. The D-dimer concentration in FIGO stage II subgroup was lower compared to stage III and IV endometrial cancer. The level of D-dimer may be useful for disease staging. Patients should receive more treatments when a higher D-dimer levelis present. Moreover, endometrial cancer PD patients had an effectively higher D2 than SD patients. The D2 was higher in patients with PD while the D2 was lower in the patients with SD. Our data revealed that D-dimer might be important factors of patient prognosis and tumor response to IMRT.

The mechanism underlying the progression of endometrial cancer by D-dimer remains uncler. Nevertheless, the different D-dimer signaling pathways may play some roles. The abnormality of haemostasis and fibrinolysis during tumor development and progression illustrated the relationship between D-dimer levels and endometrial cancer progression [15-17]. Fbrinogen could be converted to fbrin by tumor cells and D-dimer is a degradation product of fibrinogen which increased in ongoing fbrinogen metabolism [18-20]. Enhanced expression of tissue factor, which is still expressed by tumor cells, could stimulate coagulation cascades and finally result in varieties of pathological processes, such as tumor progression, angiogenesis, and metastasis [15].

Nevertheless, some limitations should be paid attention in this study. This study is a retrospective and singleinstitution study. Another limitation is the small smaple size. The small cohort size may be insufficient statistical power to detect differences, and lack of generalisability to the wider population. The third limitation is that the data on venous thromboembolism (VTE) were not collected because D-dimer can predict VTE in cancer patients [21, 22]. It has been reported that both D-dimer and VTE are adverse prognostic indicator for cancer patients [23].

In summary, our data indicate that D-dimer levels before and after IMRT D-dimer is correlated with OS and PFS in endometrial cancer patients. Additionally, the D2 is associated with survival rate in patient with endometrial cancer. We demonstrated that D-dimer levels could be also used to assess prognosis and IMRT response in endometrial cancer patients. Further prospective research is needed to make sure these discoveries.

\section{MATERIALS AND METHODS}

\section{Patients and clinical follow-up}

The data of 40 patients with endometrial cancer patients in Shanghai Jiao Tong University Affiliated Sixth People's Hospital between 2006 and 2009 were collected in our study. The inclusion criteria of this study were 
the following: (1) patients with histological confirmed endometrial cancer based on the FIGO; (2) no previous treatment; (3) no previous others malignancies; and (4) none of the patients had taken in any anticoagulant drugs before enrollment. Ethical approval for the study protocols was obtained and informed consents were obtained from each patient. The mean follow-up period for these patients was 57 months (range: 9-84 months). All patients were followed up by determination of three monthly ultrasonography (US), computed tomography (CT) or magnetic resonance imaging (MRI) scan. The diagnosis of recurrence and metastases was based on two factors: histopathological findings of the tumor tissue in patients and on the characteristic appearance on US, CT and MRI.

\section{Data collection}

We collected clinical data including age, BMI, FIGO stage, histologic grade, depths of MI, lymph node metastasis, KPS score, OS and PFS time and so on. D-dimer levels were detected before and after IMRT.

\section{Statistical analysis}

Statistical analysis used the SPSS version 19.0 statistical software. Survival analysis was performed using the Kaplan-Meier method, and the log-rank test was used for analysis. Univariate and multivariate analyses were performed using Cox's proportional hazards model. The relationship between D-dimer levels and clinicopathological features were analyzed using $\chi 2$ test. The data are expressed as the mean \pm SEM, and $P$ value $<$ 0.05 was considered statistically.

\section{ACKNOWLEDGMENTS}

Xiaojing Yang is the recipient of a grant of Shanghai Jiao Tong University Affiliated Sixth People's Hospital (contract grant number: ynlc201601).

\section{CONFLICTS OF INTEREST}

The authors declare that they have no conflicts of interest.

\section{REFERENCES}

1. Marchetti C, Piacenti I, Imperiale L, De Felice F, Boccia S, Di Donato V, Perniola G, Monti M, Palaia I, Muzii L, and Benedetti Panici P. Ixabepilone for the treatment of endometrial cancer. Expert Opin Investig Drugs. 2016; 25: 613-8.

2. He S, Gill BS, Heron DE, Kelley JL, Sukumvanich P, Olawaiye AB, Edwards RP, Comerci J, and Beriwal S.
Long-term outcomes using adjuvant pelvic intensity modulated radiation therapy (IMRT) for endometrial carcinoma. Pract Radiat Oncol. 2016.

3. Liu T, Tan S, Xu Y, Meng F, Yang C, and Lou G. Increased NUCKS expression is a risk factor for poor prognosis and recurrence in endometrial cancer. Am J Cancer Res. 2015; 5: 3659-67.

4. van Es N, Sturk A, Middeldorp S, and Nieuwland R. Effects of cancer on platelets. Semin Oncol. 2014; 41: 311-8.

5. Mego M, Karaba M, Minarik G, Benca J, Sedlackova T, Tothova L, Vlkova B, Cierna Z, Janega P, Luha J, Gronesova P, Pindak D, Fridrichova I, et al. Relationship between circulating tumor cells, blood coagulation, and urokinase-plasminogen-activator system in early breast cancer patients. Breast J. 2015; 21: 155-60.

6. Ay C, Dunkler D, Pirker R, Thaler J, Quehenberger P, Wagner O, Zielinski C, and Pabinger I. High D-dimer levels are associated with poor prognosis in cancer patients. Haematologica. 2012; 97: 1158-64.

7. Tinholt M, Sandset PM, Mowinckel MC, Garred O, Sahlberg KK, Kristensen VN, Borresen-Dale AL, Jacobsen AF, Skretting G, and Iversen N. Determinants of acquired activated protein $\mathrm{C}$ resistance and D-dimer in breast cancer. Thromb Res. 2016; 145: 78-83.

8. Go SI, Lee MJ, Lee WS, Choi HJ, Lee US, Kim RB, Kang MH, Kim HG, Lee GW, Kang JH, Lee JH, and Kim SJ. D-Dimer Can Serve as a Prognostic and Predictive Biomarker for Metastatic Gastric Cancer Treated by Chemotherapy. Medicine (Baltimore). 2015; 94: e951.

9. Zhu L, Liu B, Zhao Y, Liu L, Yang C, Yang Y, and Zhong H. High levels of D-dimer correlated with disease status and poor prognosis of inoperable metastatic colorectal cancer patients treated with bevacizumab. J Cancer Res Ther. 2014; 10: 246-51.

10. Chen Y, Yu H, Wu C, Li J, Jiao S, Hu Y, Tao H, Wu B, and Li A. Prognostic value of plasma D-dimer levels in patients with small-cell lung cancer. Biomed Pharmacother. 2016; 81: 210-7.

11. Chen WH, Tang LQ, Wang FW, Li CP, Tian XP, Huang XX, Mai SJ, Liao YJ, Deng HX, Chen QY, Liu H, Zhang L, Guo $\mathrm{SS}$, et al. Elevated levels of plasma D-dimer predict a worse outcome in patients with nasopharyngeal carcinoma. BMC Cancer. 2014; 14: 583.

12. Falanga A, Marchetti M, and Vignoli A. Coagulation and cancer: biological and clinical aspects. J Thromb Haemost. 2013; 11: 223-33.

13. Feng JF, Yang X, Chen S, Zhao Q, and Chen QX. Prognostic Value of Plasma D-dimer in Patients with Resectable Esophageal Squamous Cell Carcinoma in China. J Cancer. 2016; 7: 1663-1667.

14. Khoury JD, Adcock DM, Chan F, Symanowski JT, Tiefenbacher S, Goodman O, Paz L, Ma Y, Ward DC, Vogelzang NJ, and Fink LM. Increases in quantitative D-dimer levels correlate with progressive disease better 
than circulating tumor cell counts in patients with refractory prostate cancer. Am J Clin Pathol. 2010; 134: 964-9.

15. Kasthuri RS, Taubman MB, and Mackman N. Role of tissue factor in cancer. J Clin Oncol. 2009; 27: 4834-8.

16. Ruf W, Disse J, Carneiro-Lobo TC, Yokota N, and Schaffner F. Tissue factor and cell signalling in cancer progression and thrombosis. J Thromb Haemost. 2011; 9: 306-15.

17. Rak J, Milsom C, Magnus N, and Yu J. Tissue factor in tumour progression. Best Pract Res Clin Haematol. 2009; 22: 71-83.

18. Yamahata H, Takeshima H, Kuratsu J, Sarker KP, Tanioka K, Wakimaru N, Nakata M, Kitajima I, and Maruyama I. The role of thrombin in the neo-vascularization of malignant gliomas: an intrinsic modulator for the up-regulation of vascular endothelial growth factor. Int J Oncol. 2002; 20: 921-8.

19. Naderi M, Tabibian S, Menegatti M, Kalantar E, Kazemi A, Zaker F, and Dorgalaleh A. Disseminated intravascular coagulation with positive D-dimer: a controversial clinical feature in severe congenital factor XIII deficiency in southeast Iran. Blood Coagul Fibrinolysis. 2016.
20. Crippa L, D'Angelo SV, Tomassini L, Rizzi B, D'Alessandro G, and D'Angelo A. The utility and costeffectiveness of D-dimer measurements in the diagnosis of deep vein thrombosis. Haematologica. 1997; 82: 446-51.

21. Ay C, Vormittag R, Dunkler D, Simanek R, Chiriac AL, Drach J, Quehenberger P, Wagner O, Zielinski C, and Pabinger I. D-dimer and prothrombin fragment $1+2$ predict venous thromboembolism in patients with cancer: results from the Vienna Cancer and Thrombosis Study. J Clin Oncol. 2009; 27: 4124-9.

22. Arpaia G, Carpenedo M, Verga M, Mastrogiacomo O, Fagnani D, Lanfredini M, Milani M, and Cimminiello C. D-dimer before chemotherapy might predict venous thromboembolism. Blood Coagul Fibrinolysis. 2009; 20: 170-5.

23. Tyack PL, Calambokidis J, Friedlaender A, Goldbogen J, and Southall B. Formal Comment on Schorr GS, Falcone EA, Moretti DJ, Andrews RD (2014) First Long-Term Behavioral Records from Cuvier's Beaked Whales (Ziphius cavirostris) Reveal Record-Breaking Dives. PLoS ONE 9: e92633. doi:10.1371/journal.pone.0092633. PLoS One. 2015; 10: e0142287. 